\author{
Stavros Assimakopoulos \\ Rebecca Vella Muskat \\ University of Malta
}

\title{
EXPLORING XENOPHOBIC AND HOMOPHOBIC ATTITUDES IN MALTA: LINKING THE PERCEPTION OF SOCIAL PRACTICE WITH TEXTUAL ANALYSIS
}

\begin{abstract}
Reporting on research undertaken under the auspices of the C.O.N.T.A.C.T. project, the present paper investigates the roots of xenophobic and homophobic attitudes in Malta and the extent to which these can be pinpointed in the lexical choices made in discriminatory comments posted online in reaction to local news stories pertaining to migrants and members of the LGBTIQ community. Adopting Fairclough's threedimensional framework (1995), we start off by presenting the values that underlie local discriminatory attitudes as social practice, as these were identified by the participants of four focus group interviews that were conducted at the University of Malta. In this respect, while xenophobia seems to be a far more pressing issue in Malta, homophobia, which is still also present, is taken to be predominantly triggered by deep-rooted religious beliefs and allegiance to heteronormative values. Then, when it comes to xenophobia, the main relevant trigger seems to be the perceived threat that the different collective background of a particular subset of migrants in Malta poses to the local culture. In an attempt to show that these values can also be discerned by examining even the most basic textual characteristics of a dataset comprising xenophobic and homophobic talk in the local context, we turn to identify them by looking at quantitative measures pertaining to lexical choice and metaphorical extension in the relevant parts of our corpus. In this way, we provide evidence for the fundamental - for Critical Discourse Analysis - claim that the textual analysis of a relevant dataset can indeed reveal the axiological framework that underlies the negative stance that the general population may have in relation to particular minorities, showcasing the relevance of discourse analytic methods for the broader understanding of discrimination and hate speech.
\end{abstract}

\section{Keywords}

Critical Discourse Analysis, identity construction, discriminatory discourse, news portal comments, lexical choice, metaphor, hate speech, migrants, LGBTIQ, hate speech 


\section{Introduction}

"The centrality of language as a means of social construction" (Teo 2000: 11) has been consistently acknowledged by researchers in the area of Critical Discourse Analysis, which offers researchers tools that will enable them to observe how and why certain discourses are produced in a particular social context, by identifying the textual elements that contribute to the construction of particular ideologies. As Fairclough further elucidates, "critical approaches differ from non-critical approaches in not just describing discursive practices, but also showing how discourse is shaped by relations of power and ideologies, and the constructive effects discourse has upon social identities, social relations and systems of knowledge and belief, neither of which is normally apparent to discourse participants" (Fairclough 1992: 12). In this vein, the present paper seeks to uncover the mechanisms of identity construction framed within a discourse of Us vs. Them in the context of migrant and LGBTIQ minorities in Malta.

Following on from the observation that, much like all other forms of discrimination, "racism is socially learned, and discourse is essential in the process of its ideological production and reproduction" (van Dijk 1995: 3), we attempt to pinpoint the main values that underlie the aforementioned ideological constructions, as these are perceived by members of the general population, in the language used in the comment sections of online news portals in Malta. The upshot of our argument is that both the ideological construction of minorities as out-groups and some of the main underlying reasons for it can be straightforwardly identified through an analysis of even the most basic textual elements of representative samples from the relevant discourse. In our case, these samples are online comments that express a negative attitude towards migrants and LGBTIQ persons in Malta, which are included in the corpus of local news portal articles and comments that we compiled and analysed for the purposes of the EU co-funded C.O.N.T.A.C.T. project. ${ }^{1}$

Our overall argumentation in this paper is to be placed within Fairclough's tripartite model (detailed in Fairclough 1995, among many other publications by the same author), according to which discourse is best viewed as a concept that places texts within discursive and social practices. And the placement of discourse in the particular discursive practice of engaging in online commentary is extremely important given our present aim. In this regard, the choice to focus on online comments made by the general public in reaction to news stories pertaining to LGBTIQ and migration issues, rather than the stories themselves, as several scholars before us have done, was certainly not coincidental. We believe that this particular kind of computer-mediated communication naturally lends itself to critical analyses of the ideological stances that underlie discrimination for various reasons. For one, the internet is a prime location for the discovery of discriminatory discourse; as Josey asserts, it "represents one of the few safe

\footnotetext{
${ }^{1}$ For further information about the C.O.N.T.A.C.T. project, visit http://reportinghate.eu.
} 
spaces for extremely divergent opinions on race, politics and society", since "as a decentralized media, controlled by the end user, it has allowed a resurgence in the solidarity and power building of hate-based groups" (2010: 37). Along the same lines, "numerous authors ${ }^{2}$ have pointed to the increase of hate speech in news websites' comments and have emphasized the need for analyses of hate speech in news websites' comments" (Erjavec and Kovačič 2012: 900). Then, the relevant discourse enables us to access the opinions of the general public in a form that is usually unfiltered, when compared to these opinions being reported by a journalist. Even barring the deletion of some comments by the relevant portals' moderators, the posting of comments with controversial content is often allowed "as a means of keeping old and attracting new users of online news media" (Erjavec and Kovačič 2012: 901). Finally, and perhaps most importantly, the casual nature of the language used by most commentators is more prone to spontaneously express the writer's true feelings when compared to an opinion article that has been carefully proofed prior to publication. All in all, we think that it is precisely because of the language used in online comments to news stories being a "written-spoken hybrid" (Rowe 2009: 85) akin to that used in social media communications, that even a superficial analysis of its basic textual characteristics can provide significant insights into the ideological background of its writer. ${ }^{3}$

Against this backdrop, in this paper, we will follow a practice that may seem rather unconventional when it comes to reporting research in Critical Discourse Analysis; we will be moving from the (public perception of the) level of social practice to the level of textual analysis. This will be done with a view to showing that the broader ideological stances held in relation to discriminatory attitudes can indeed be revealed to a considerable extent through the analysis of even the most general textual characteristics of a particular type of discourse, as long as this discourse comprises spontaneous talk that mirrors the general sentiment of a particular population. To this end, our starting point will be the focus group interviews that we conducted at the University of Malta towards the end of the C.O.N.T.A.C.T. project. While both our analysis of online comments in reaction to news stories in the domains under question and the local administration of a questionnaire on hate speech/crime preceded these interviews, what soon became evident while analysing the obtained interview data was that the discussion that took place during the focus group interviews independently corroborates our findings in relation to local discriminatory discourse targeting the two groups at hand. So, after identifying the main themes pertinent to identity construction that arose during the interviews, we will turn to show how they can also be independently revealed through the examination of lexical choice and metaphorical extension in online comments to local news stories that communicate a negative stance towards the two minorities under question. In this respect, the present paper is best seen as an effort to provide some concrete evidence for the

\footnotetext{
${ }^{2}$ See, for example, Cammaerts (2009), Domingo et al. (2008).

${ }^{3}$ For a discussion of the link between public perception and discriminatory comments posted online in reaction to news stories, see Kopytowska et al. (2017).
} 
underlying assumption in Critical Discourse Analysis that the analysis of the language that is embedded within a carefully and objectively sampled relevant discourse can indeed reveal the outlook that society has in relation to the groups this discourse discusses. ${ }^{4}$

\section{The public perception of the axiological dimension of xenophobia and homophobia in Malta}

The focus group interviews with members of the general public that took place at the University of Malta in May-June 2017 aimed to help us gain a deeper understanding of the results obtained through the previous administration of a survey on hate speech and discriminatory discourse in the local context. The relevant survey, to which 209 participants responded, followed the common C.O.N.T.A.C.T. methodology (cf. Millar et al. 2017), and asked participants to rate six examples of discriminatory comments found in reaction to news articles in the local press in terms of their acceptability, before offering them a chance to share their own experiences as witnesses, or even targets of such discourse in Malta and eventually comment on their perceived applicability of different definitions of hate speech in a legal setting. ${ }^{5}$ During the subsequent focus group interviews, which also followed the semi-structured format prescribed by the common project methodology (cf. ibid), participants were encouraged to discuss the results obtained from the survey and hypothesise about the reasons why they think these were so. Crucially, no information about the previous part of the research that involved the analysis of online comments to news portal stories was divulged to participants during these interviews. All in all, 4 focus group interviews with 21 participants, 11 female and 10 male, were conducted for this strand of the C.O.N.T.A.C.T. research. Sixteen of the participants were below 35 years of age, which was the target group according to the common methodology. Our focus groups comprised 13 Maltese, $6 \mathrm{EU}$ and 2 non-EU nationals, and in terms of occupation, 10 interviewees were students, 4 academics and 2 employed in administrative positions at the University of Malta. Out of the remaining 5 participants, 2 were artists, with the rest being a computer programmer, a marketing consultant and a taxi driver respectively. ${ }^{6}$ All focus group interviews, which lasted on

\footnotetext{
${ }^{4}$ For a discussion of this assumption over and above Fairclough's framework, with a special focus on the relevant concept of triangulation in the discourse-historical approach, see Wodak and Meyer (2009).

${ }^{5}$ For a presentation and discussion of the collected questionnaire responses, see Assimakopoulos and Vella Muskat (2017: 22-36).

${ }^{6}$ Apart from the usual restrictions involved in the recruitment of interview participants, in terms of the researchers' access to particular groups of participants and the participants' availability itself, the demographics of our group for this study aimed at matching as much as possible the demographics of the respondents to the Maltese C.O.N.T.A.C.T. questionnaire that preceded it. In light of this, we
} 
average 45 minutes each, were recorded using unobtrusive audio equipment and then transcribed in order to facilitate further analysis.

Overall, there was broad consensus amongst our interviewees that xenophobia is a far greater issue than homophobia in Malta. While this is a conclusion that had also arisen during all the previous stages of our research, what we will be focusing on in this section are the main reasons to which our interview participants attributed this observation. ${ }^{7}$ This will then enable us to turn, in the following section, to the textual features of our collected corpus of online comments that communicate a negative attitude towards the minorities under question with a view to showing how the particular values that emerged during the focus group interviews can also be independently revealed through them.

\subsection{Emerging ideological values}

As already mentioned above, most of our interviewees seemed to be in agreement with the general conclusions of the Maltese strand of the C.O.N.T.A.C.T. research, since they confirmed that, in their experience, homophobia has become less of an issue locally in recent years, while xenophobia is steadily following the opposite trend.

[Discussing a comment in relation to the LGBTIQ community] ...I think it shows as well that people in Malta are less homophobic than they are racist.

(Interviewee 3, Focus Group 1)

...I think here in Malta, I mean, we've come a long way and I'm not saying that the Maltese people are less homophobic now, but I mean, the numbers usually show that there's more, there's a problem with racism here in Malta than homophobia. I don't mean that there isn't a problem with homophobia by any means but, I mean, the numbers show that uh regarding homophobia there are more non acceptable results than there are in the xenophobia...

(Interviewee 6, Focus Group 2)

The most prevalent reason provided by our interviewees regarding this trend was that while the migrant minority comprises individuals who are commonly thought to have nothing in common with the Maltese in-group, most members of the LGBTIQ group are still considered to be part of it, by virtue of sharing the same nationality with its members, even though they additionally form part of their own minority too.

purposefully recruited more female than male participants, as well as more participants of Maltese descent or of higher education experience than not [for demographic information about the questionnaire respondents, cf. Assimakopoulos and Vella Muskat (2017: 22-23)].

${ }^{7}$ Other issues that were discussed during the focus group interviews, but which go beyond the scope of the present paper, included the interviewees' experience with discriminatory discourse as well as their thoughts about what actually constitutes hate speech and whether and how it should be regulated (cf. Assimakopoulos and Vella Muskat 2017: 36-44). 
...it's sort of like [...] immigrants are external, an external part of us sort of. While homosexuals are an internal part.

(Interviewee 21, Focus Group 4)

...the homophobic issue [...] also affects a lot of families because a lot of families have one or two of their children or someone from their family who's part of that minority group, so they are more likely to defend that minority group [...]. Very few families actually have a child or a member of the family who's from Asia or from an Arabic country, for example, so it's more of an 'us' and 'them' mentality while homophobia is more of a 'they're part of us, they're still Maltese at the end of the day'...

(Interviewee 1, Focus Group 1)

...people are coming out of their shells, like 'hey I'm gay' ok, so now it's acceptable. And now families, like Maltese families, they have family members who are also gay, so they've become more acceptable. So, that's closer to home I guess, because they're part of us, they're our family. So, ok, we can accept them, but they're from another culture, they're Arabs, Muslim...

(Interviewee 5, Focus Group 1)

In this setting, examples (4) and (5) also indirectly serve to illustrate an additional conclusion that was also reached through the collective research that we carried out under the auspices of the C.O.N.T.A.C.T. project; that is, that most xenophobic discourse identified in the local context appears to predominantly target a particular sub-group of the migrant minority in Malta: that of migrants of a Muslim persuasion and/or an Arab or African ethnic origin. This much was asserted by several of our interviewees, who also pointed out that migrants from, say, Western and Northern Europe do not generally face the same amount of intolerance and discrimination in Malta.

...they're the same, I think, because, maybe in terms of culture, there's a lot more similarity between a Maltese and a European.

(Interviewee 1, Focus Group 1)

...if you look European, you know, you're, let's face it, you're just less likely to be the target of racial slurs, if you're white...

(Interviewee 15, Focus Group 3)

Overall, this distinction between different groups of migrants in Malta seems to stem from the conviction that, while Western and Northern Europeans "blend in" more successfully with the local population, the targeted group of migrants stands out both physically and culturally. This, in turn, leads to an often observed conflation of a person's identity on grounds of religion, skin colour and ethnicity, whereby one might be a black Ethiopian Christian, but by virtue of being black and African they can easily be categorised as Muslims. 
Special issue on The pragmatics of othering: Stereotyping, hate speech and legitimising violence

DOI:10.1515/lpp-2017-0010

Even when you hear people talking about immigrants, they talk about the blacks, while the majority, the major, sorry... the majority of immigrants that come to Malta are actually Arabs. They have the same skin colour as us. Most people actually live next door and they don't even know. But when they see a black man for example, they tend to discriminate against them, even on the work place. I've seen this many times.

(Interviewee 20, Focus Group 4)

....any article about Islam is bound, you know there's a small group of people that spends a lot of time, I think um, commenting on the newspaper...

(Interviewee 15, Focus Group 3)

...people will not sit next to a black guy on a bus. For example, if there's nowhere else to sit, they might just stand.

(Interviewee 13, Focus Group 3)

[Talking about the local population] ...they're more likely to hang out with someone of the opposite sex than someone who's black or someone who's Arab. I mean, it's about who you choose to sort of hang out with...

(Interviewee 18, Focus Group 4)

This brings us to the main value that was singled out by our interviewees in relation to xenophobia in Malta, and which seems to revolve around the more general themes of integration and multiculturalism. In fact, both the responses collected through our questionnaire administration and the discussion that took place during the focus group interviews indicated that there is a marked tendency to defend opinions that appear to be protective of the Maltese culture against other cultures that are perceived to be different from it $^{8}$. In this vein, multiculturalism might not be negative by virtue of what it stands for, but becomes undesirable when it seemingly pushes the Maltese culture, as the dominant and most visible culture of the country, to the side, effectively becoming a threat in the conscience of the general population. Therefore, it may be less acceptable to directly attack a person on the basis of a minority identity, but when one does this trying to defend and protect one's culture or even personal prosperity, it is more acceptable to use such rhetoric.

"...in the case of the multiculturalism thing, there's also the fact that people feel under threat. Nobody really feels under threat because somebody is gay." ... "Really homophobic people find it scary because it's a matter of thinking of this as unnatural and maybe feeling disgusted by it or whatever reason, but in the case of the multiculturalism this starts getting into, you know, this is about my job right. This is about my family. it's about money in my pocket." (Interviewee 15, Focus Group 3)

${ }^{8}$ It should be noted that this is a recurring theme in several studies on the effects of the perceived national identity to social practice (cf. Triandafyllidou 2000; Reisigl and Wodak 2001; De Beaugrande 2004; Kopytowska, Woźniak and Grabowski 2017). 
...even for people who are, have no problems with Muslims per se, but then, when you start seeing your, I guess, people feel nervous when they see their neighbourhood being transformed um, you know, with the appearance of a mosque for instance, um, they feel uncomfortable with that. So, less people would be inclined to say, you know, that, less people would be inclined to defend immigrants who are calling for these changes.

(Interviewee 1, Focus Group 1)

[Comparing a comment that provides a general opinion about multiculturalism to a comment that outright condemns it] ...the comments are defending the people who are actually going to see the comment so they are less likely to say it's a bad comment, while the other one he's attacking directly the people rather than just analysing the situation from a 'I want to protect my culture' point of view.

(Interviewee 20, Focus Group 4)

Along similar lines, the negative stance toward the minorities of migrants targeted most by xenophobic comments is also likely due to the assumption that they do not appear to assimilate as well into Maltese society as European migrants do, when this is what is expected by the local population.

...it's easier for them [=Europeans] to assimilate, not to integrate. We expect them $[=\mathrm{Arab}$ and African migrants] to assimilate, not integrate.

(Interviewee 3, Focus Group 1)

When it comes to the issue of the far less noticeable, but still existent, homophobic attitudes that can be traced in the Maltese context, their main roots, as these were identified by our focus group participants, tend to be related to religious concerns, and more specifically what the general public takes to be the conviction of the church regarding members of the LGBTIQ community. In this view, people might be less inclined to mark a comment as discriminatory or hateful if that comment somehow involves the church; for, if the comment is in line with the church doctrine, the comment must be right, or at the very least, make sense.

[Discussing the three comments that were included in the local survey in relation to homophobia] ...the third one is more acceptable to people because it's, the context is less religious. The other two are religious stories, the first one about the church's commission, and the second one about um, the Dominican order, but the third one is about legislation, so it may be that um people find it more acceptable...

(Interviewee 4, Focus Group 1)

...Cause that's how the majority of Maltese people behave unfortunately. If it's condoned by the church 'oh, it's ok'...

(Interviewee 6, Focus Group 2) 
In this particular setting, the reservations on the basis of religion appear to complement a more general heteronormative perception, common among individuals who show a negative disposition towards members of the LGBTIQ community, and, according to which, homosexuality is effectively an unnatural and abnormal behavioural choice rather than a natural trait that some individuals are born with.

...like the ones about homosexuality, they attack sort of the nature of homosexuality, whether it's natural to sort of be gay

(Interviewee 18, Focus Group 4)

[Discussing homosexuality] It might disgust you, but you'll stay away from it.

(Interviewee 15, Focus Group 3)

All in all, apart from confirming that xenophobia is far more prominent than homophobia in the Maltese context, our focus group interview discussions also provided considerable insights into the roots of both xenophobia and homophobia in the country. In summary, these seem to be: (i) the exclusion of (a particular subset of) the migrant minority from - and parallel inclusion of the LGBTIQ community to - the Maltese ingroup; (ii) the perception of multiculturalism, or any attempt to integrate the same minority for that matter, as an imminent threat to the local culture and the prosperity of the Maltese, and (iii) the rejection of the LGBTIQ group on the basis of religious reservations or the perception of homosexuality as unnatural.

\section{Investigating discriminatory stances in online comments posted under news portal stories}

Having identified the main axiological context that, according to our focus group interview participants, underlies xenophobic and homophobic attitudes on the Maltese islands, it is now time to turn to show how the particular values that it consists in can also be discerned when looking at the textual level of discriminatory statements produced in the local context. To this end, we will be employing the local corpus of online comments that we compiled as part of the C.O.N.T.A.C.T. project; a corpus that comprises comments posted in reaction to articles pertaining to migration and LGBTIQ matters that were published in Maltese news portals. But before we turn to the examination of its contents that interest us, it is essential to briefly outline the procedure followed for the corpus population and eventual analysis.

\subsection{Corpus population and analysis}

In line, again, with the common C.O.N.T.A.C.T. methodology (cf. Millar et al. in 2017), the samples of data that we collected for the C.O.N.T.A.C.T. project in order to observe 
and analyse patterns in hate speech and discriminatory discourse pertaining to xenophobia and homophobia in Malta, comprise news stories and associated comments posted in reaction to them in local news portals ${ }^{9}$.

To begin with, we used the European Media Monitoring tool (henceforth EMM) ${ }^{10}$ a global database of online news portals that has been developed by the Joint Research Centre of the European Union and allows users to input keyword (or phrase) searches within the limits of specific dates, source countries, languages, and newspapers. As the C.O.N.T.A.C.T. project has been concerned with understanding and analysing xenophobic and homophobic talk, we performed the relevant search for Malta by using a number of keywords, some of which were agreed upon jointly by the project partners (such as "gay" or "migrant"), with the rest being country-specific, like, for example, "black", which, while not necessarily a keyword pertaining to migrants in all EU countries, is particularly relevant in the local context, as it is often used to refer to migrants on the Maltese islands. The relevant searches were performed over a six-month period that comprised April, May, June and December 2015 as well as January and February 2016, and by the end of this process, we had collected the urls of all articles in Maltese news portals that contained each of the predetermined keywords in the aforementioned time frame.

However, not all the articles retrieved through this search got selected for inclusion in our corpus. In order to populate the corpus with a manageable, yet representative enough sample of articles and associated comments, we selected the 8 keywords that returned most hits in the EMM search in each one of the migration and the LGBTIQ domains. In this regard, we deviated slightly from the common C.O.N.T.A.C.T. methodology that prescribed the selection of 8 keywords for migration and 6 for LGBTIQ matters, but we did so in order to end up with balanced sets of data across the two domains. Against this background, the keywords used to populate the Maltese C.O.N.T.A.C.T corpus were: "gay/s" "11, "gender identity", "homophobia", "homosexual/s", "lesbian/s", "LGBT/IQ",

\footnotetext{
${ }^{9}$ Even though we collected and analysed articles and comments from news portals in both English and Maltese for the purposes of the C.O.N.T.A.C.T. project, the present analysis is based solely on the content retrieved from English-language portals. The reason that this decision was made was that apart from being notably less popular in terms of everyday traffic than their English counterparts, Maltese-language portals also tend to attract far less comments under their stories. So, even after including all retrieved Maltese-language articles with comments and their associated comments in our corpus, we were nowhere near the requisite 5,000-word threshold per keyword in either articles or comments for any one of the selected keywords. In the interest of basing our present argumentation on a balanced dataset, we have decided not to use the dataset pertaining to Malteselanguage news portals for our present purposes; so, for ease of exposition, we will henceforth be referring to the C.O.N.T.A.C.T. corpus for Malta, as if it only contains data from English-language portals.

${ }^{10} \mathrm{http} / / / \mathrm{emm}$. newsbrief.eu

${ }^{11}$ The searches performed with the EMM engine included all keywords in both their singular and plural form (when this is available in language), since each of them often returned different articles.
} 
Special issue on The pragmatics of othering: Stereotyping, hate speech and legitimising violence

DOI:10.1515/lpp-2017-0010

"sexual orientation", and "transgender/s" for the LGBTIQ domain; and "asylum seeker/s", "black/s", "immigrant/s", "immigration", "migrant/s", "Muslim/s", "race" and "refugee/s" for the migration one. Once we eliminated all articles that included all the remaining keywords from our original search, we went on to order the updated url list on the basis of the number of comments that had been posted beneath each article within it. Using this number of comments per article as our primary criterion, and after removing from the list articles that were irrelevant to the topics under question ${ }^{12}$, we finally embarked upon collecting 5,000 words worth of articles, alongside an additional 5,000 words worth of associated comments (evenly distributed across the selected articles) per keyword. Through this process we managed to compile a balanced corpus of articles and associated comments pertaining to migration and LGBTIQ issues.

Table 1: Overview of the C.O.N.T.A.C.T. corpus for Malta.

\begin{tabular}{|c|c|c|c|c|}
\hline Domain & $\begin{array}{c}\text { No of } \\
\text { articles in } \\
\text { corpus }\end{array}$ & $\begin{array}{c}\text { Size of article subcorpus } \\
\text { (in words) }\end{array}$ & $\begin{array}{c}\text { No of comments } \\
\text { in corpus }\end{array}$ & $\begin{array}{c}\text { Size of comments } \\
\text { subcorpus (in } \\
\text { words) }\end{array}$ \\
\hline LGBTIQ & 80 & 42273 & 1109 & 40924 \\
\hline Migration & 79 & 41006 & 1130 & 41020 \\
\hline
\end{tabular}

Once our corpus was compiled, all articles and comments therein were annotated in terms of their evaluative content, following the common C.O.N.T.A.C.T. methodology. In the first instance, each article was marked as communicating a positive, negative or neutral stance towards the minorities under question, and then each one of its associated comments in the corpus was also annotated along the same lines. What is particularly important to note is that during this process, which was independently undertaken by both authors of this paper to ensure reliability, we focused exclusively on the attitudes expressed in relation to migrants and members of the LGBTIQ community, marking any evaluative content related to a different target, such as politicians, the church or other commentators, as irrelevant. Once each comment was labelled in terms of its polarity, the conceptual tactics used by its writer to communicate a positive or negative attitude were also identified, following several categories established by the joint C.O.N.T.A.C.T. methodology, and exemplified in Table 2 that follows.

What, as discussed in footnote 6 above, the same searches were also repeated for the Maltese counterparts of the keywords under investigation.

${ }^{12}$ Some of the articles retrieved through the EMM search were indeed irrelevant for our present purposes. To give a characteristic example, one article that was retrieved under the keyword "black" focused on Darth Vader and the new Star Wars film, which is obviously a topic completely unrelated to the migration. 
Table 2: Classification of comment tactics on the basis of the C.O.N.T.A.C.T. methodology.

\begin{tabular}{|l|l|}
\hline Annotated tactic & Example from the Maltese corpus \\
\hline $\begin{array}{l}\text { Agreement with } \\
\text { negative news } \\
\text { reported }\end{array}$ & $\begin{array}{l}\text { "This is only the beginning. The worse has yet to come. Who knows how many } \\
\text { of those illegal immigrants and refugees belong to ISIS or Al Queda." }\end{array}$ \\
\hline $\begin{array}{l}\text { Counterstatement to a } \\
\text { negative statement }\end{array}$ & "What do you think homosexuals are exactly? Animals?" \\
\hline $\begin{array}{l}\text { Counterstatement to } \\
\text { news report }\end{array}$ & $\begin{array}{l}\text { "Such a vile, hate-filled rant is typically associated with far-right hate groups or } \\
\text { religious extremists." }\end{array}$ \\
\hline Generalisation & $\begin{array}{l}\text { "This sort of person is the type 'they' want us to integrate with 'us"? He didn't } \\
\text { even pay for a normal driving licence." }\end{array}$ \\
\hline Insult & "If anyone is lacking, it is you guys for lacking a sense of decency." \\
\hline Metaphor & $\begin{array}{l}\text { [Metaphor of unnaturalness] } \\
\text { "Is there a limit to this modern attempt to eradicate any semblance of order in } \\
\text { sexual human behaviour?" }\end{array}$ \\
\hline $\begin{array}{l}\text { Negative } \\
\text { categorisation }\end{array}$ & \begin{tabular}{l} 
"That's the gratitude one gets from the savage African continent." \\
\hline Negative implicature
\end{tabular} $\begin{array}{l}\text { "So now they are thinking more about the minority and forget about the } \\
\text { majority!!!" }\end{array}$ \\
\hline Positive implicature & $\begin{array}{l}\text { "LGBT are already there, and they're getting mercilessly killed. There's nothing } \\
\text { funny about it." }\end{array}$ \\
\hline Positive words & "Great the LGBT are doing so well." \\
\hline Stereotype & $\begin{array}{l}\text { "And then some of them escape to our country and when they settle down they } \\
\text { demand the application of Sharia Law on us." }\end{array}$ \\
\hline Suggestion & $\begin{array}{l}\text { "There is only one solution: to prevent the boats from leaving Libya and to send } \\
\text { back those that leave." }\end{array}$ \\
\hline
\end{tabular}

\subsection{Locating stance in the overall corpus}

Having presented the methods used for the compilation and annotation of the Maltese C.O.N.T.A.C.T. corpus, we are now ready to showcase on its basis how the three main values that were identified by our focus group interview participants can also be found in local talk pertaining to migration and LGBTIQ matters. As a quick reminder, the main conclusions reached by our interviewees were: (i) the inclusion of the LGBTIQ persons in the in-group of the local Maltese population and parallel exclusion of migrants from it; (ii) the perception of multiculturalism as a threat for the in-group; and (iii) the rejection of the LGBTIQ community on religious and heteronormative grounds. While the last two conclusions appear to be pertinent to discriminatory discourse regarding the targeted minorities alone, the first one is obviously related to the general attitude that the public has towards the two groups under question. So, in order to see whether this particular perception of our interviewees matches the data 
analysed in our corpus, we will start by looking at the overall results of our analysis for the two domains.

In this regard, as the following pie charts clearly indicate, there may be a presence of a negative attitude towards both minorities that we are investigating here, but this attitude is far more prevalent in the case of migrants than it is in that of members of the LGBTIQ community.

Evidently, the results regarding xenophobia in Malta seem to be particularly alarming, as the negative comments in this domain are almost double in number than those that express a positive attitude in relation to this particular target group. ${ }^{13}$ What is particularly notable, however, is that the instances in which a positive attitude towards the LGBTIQ minority group was expressed substantially outnumber the corresponding negative comments. At face value, this indicates that the local population is generally accepting of LGBTIQ persons, which indirectly corroborates the opinion provided by our interviewees regarding this minority being commonly perceived as part of the local in-group.

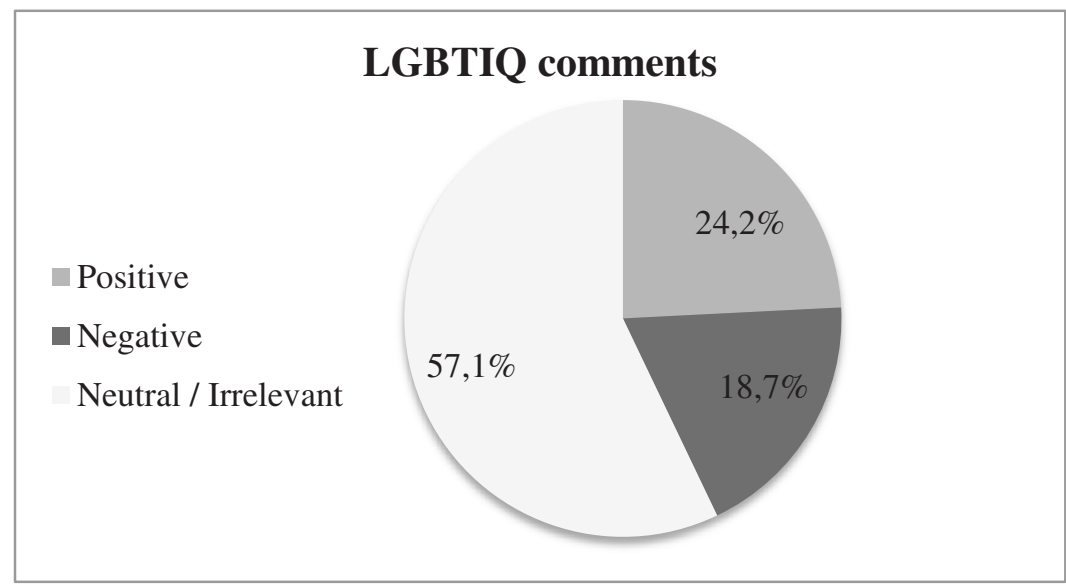

Figure 1: Results of polarity analysis for comments in the LGBTIQ domain.

\footnotetext{
${ }^{13}$ Additionally, more negative remarks about migrants, which we have not taken into account here due to our methodological constraints, were also found in the LGBTIQ corpus, which appears to suggest that in some cases xenophobia has a way of entering the picture even in seemingly irrelevant discussions.
} 


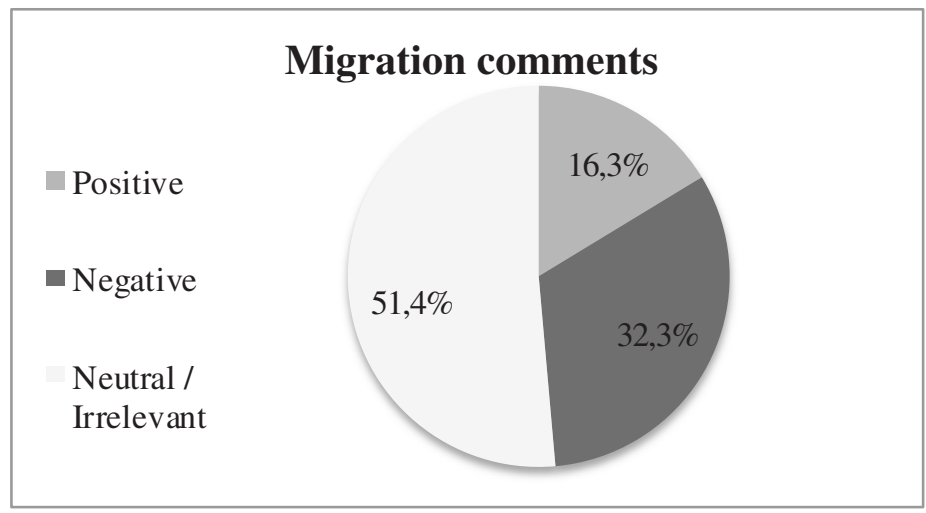

Figure 2: Results of polarity analysis for comments in the Migration domain.

With this in mind, we can now turn to see how the xenophobic and homophobic attitudes, and in particular their underlying axiological roots, that were independently identified by the same interview participants can also be pinpointed by looking at the textual level of the collected negative comments in each of the two domains. A description of the two relevant subcorpora can be found in Table 3 that follows.

Table 3: Overview of the comments with negative polarity subcorpus for Malta.

\begin{tabular}{|c|c|c|}
\hline Domain & $\begin{array}{c}\text { No of comments with negative } \\
\text { polarity in corpus }\end{array}$ & $\begin{array}{c}\text { Size of comments with negative polarity } \\
\text { subcorpus (in words) }\end{array}$ \\
\hline LGBTIQ & 207 & 11056 \\
\hline Migration & 365 & 15265 \\
\hline
\end{tabular}

\subsection{Identifying axiology in the discriminatory discourse subcorpora}

\subsubsection{Lexical choice}

For the purposes of this subsection, we will turn to analyse our subcorpora of negative comments for the two domains in terms of lexical choice. In order to analyse them, we loaded the two subcorpora to the freeware corpus analysis toolkit AntConc (Anthony 2014), and automatically generated the relevant lists that we will be focusing on in this section. As we have already noted, the analysis we will be reporting on here will be rather superficial, in that it only involves measures of frequency, but we are confident that even this alone suffices to show that the relevant values we are seeking to identify readily present themselves. All in all, the relevance of lexical choice in both corpus linguistics and discourse analysis has repeatedly been acknowledged. As far back as the 
1930s, Firth, in his account of lexical semantics, underlined the role that the distribution of lexical items pertinent to a social group plays in particular contexts as a way of identifying values associated with it (1935: 40-41). Against this backdrop, "frequencysorted word lists have long been part of the standard methodology for exploiting corpora" (Baron et al. 2009: 41). And in the particular setting of investigating emotive language in relation to minorities, lexical choice, so construed, has also been shown to have a prime bearing on the uncovering of ideology (cf. Baker et al. 2008: Baider 2013; Love and Baker 2015; Baider and Constantinou 2017; Kopytowska et al. 2017).

Starting off with an overview of the 15 content words most frequently used in each of the two subcorpora under investigation, we can easily see that, in the case of negative comments towards the LGBTIQ community, religion indeed seems to play a crucial role in the narrative, with "God" and "church" being two of the most commonly encountered lexical items in the relevant texts - and "Christ" also following not that far behind (cf. Table 4). Turning to the migrant minority, the frequency list in Table 5 may only give an indirect indication that culture plays an important role in the local xenophobic narrative, as the relevant lexical item is not one the most prominent words in the list, but the prominence of the words "Malta" and especially "Maltese" serves to suggest that reference to the local identity is particularly visible when it comes to xenophobic discourse against migrants.

What is more, the relative prevalence of the lexical items "Muslim" and "Libya" in Table 5 seems to additionally corroborate another point that was made in relation to local xenophobic attitudes; that is, that only a subset of the local migrant population seems to be the main target of xenophobic statements.

That being said, it has often been argued that the frequency of use of a particular lexical item in a corpus on its own is not a reliable measure to establish the saliency of its associated concept in the relevant discourse. As Pollach asserts, "frequency information is always most informative when corpora from different sources or different times are compared" (2012: 269). In this sense, an alternative measure that seems to be more reliable is that of keyness, which effectively targets words "whose frequency is unusually high in comparison with some norm" (Scott 1997: 53), and are thus dubbed "key words". In order to identify key words in a particular text or collection of texts, one can establish this "unusual frequency, by comparison with a reference corpus of some kind" (Scott, 1997: 236). In our particular setting, the reference corpus used to calculate keyness was that of the articles collected for the C.O.N.T.A.C.T. corpus in each domain. The rationale behind choosing this set of texts as a reference corpus was that by identifying the lexical items that are more prominent in the negative comments in comparison to those that are also contained in the - mainly neutral - articles of our corpus, we should be able to pinpoint more directly the 
concepts that underlie the negative attitude characteristic of the said comments, approximating in this way the values that underlie this attitude even more. ${ }^{14}$

Table 4: Frequency of content words in the LGBTIQ negative comments subcorpus.

\begin{tabular}{|l|l|}
\hline Expression & Frequency \\
\hline gay & 68 \\
\hline God & 50 \\
\hline church & 39 \\
\hline children & 34 \\
\hline people & 33 \\
\hline rights & 30 \\
\hline homosexual & 25 \\
\hline Christ & 21 \\
\hline human & 21 \\
\hline Malta & 21 \\
\hline want & 21 \\
\hline good & 17 \\
\hline man & 17 \\
\hline normal & 17 \\
\hline marriage & 17 \\
\hline
\end{tabular}

Table 5: Frequency of content words in the Migration negative comments subcorpus.

\begin{tabular}{|l|l|}
\hline Expression & Frequency \\
\hline country & 92 \\
\hline Malta & 71 \\
\hline people & 67 \\
\hline Maltese & 58 \\
\hline immigrants & 50 \\
\hline illegal & 45 \\
\hline Muslim & 45 \\
\hline culture & 38 \\
\hline Europe & 35 \\
\hline racist & 28 \\
\hline year & 24 \\
\hline European & 23 \\
\hline government & 19 \\
\hline immigration & 18 \\
\hline Libya & 18 \\
\hline
\end{tabular}

Indeed, as Tables 6 and 7 indicate, the conclusions already drawn in our discussion of frequency above seem to be largely on the right track, when taking into account the 15 most frequent key words in the two datasets, calculated by log-likelihood. In relation to homophobic attitudes, religion is obviously the single most prominent conceptual category in terms of keyness, with "God", "Christ" and "Bible" being highest in the list. Then, while "Malta" and "Maltese" do not appear to be key words in the corpus of negative comments towards migrants, "culture" still features very high on the list. When coupled with the lexical item "integrate", it again seems to indicate that the issues of multiculturalism and integration are central to xenophobic attitudes in Malta.

\footnotetext{
${ }^{14}$ A similar procedure was used in Kopytowska, Grabowski and Woźniak (2017) for the analysis of Polish data on refugees and migrants also collected under the auspices of the C.O.N.T.A.C.T. project.
} 
Special issue on The pragmatics of othering: Stereotyping, hate speech and legitimising violence

DOI:10.1515/lpp-2017-0010

Incidentally, the keyness scores in Table 7, and especially those obtained by the lexical items "illegal", "pushback"15, "Africans" and "desert" provide additional support for the claim that the main target of xenophobic discourse in our analysed comments is not the whole population of migrants in the country, but rather the fraction of it that includes irregular migrants, typically coming from African or Arab states in turmoil.

Table 6: Keyness of content words in the LGBTIQ negative comments subcorpus.

\begin{tabular}{|l|l|}
\hline Expression & Keyness \\
\hline God & 86.355 \\
\hline Christ & 50.476 \\
\hline Bible & 31.136 \\
\hline normal & 29.457 \\
\hline everything & 29.291 \\
\hline male & 26.109 \\
\hline gay & 24.693 \\
\hline Professor & 22.003 \\
\hline like & 21.681 \\
\hline want & 31.670 \\
\hline teaching & 21.589 \\
\hline female & 21.491 \\
\hline kids & 19.688 \\
\hline chapter & 18.860 \\
\hline wrong & 17.639 \\
\hline
\end{tabular}

Table 7: Keyness of content words in the Migration negative comments subcorpus.

\begin{tabular}{|l|l|}
\hline Expression & Keyness \\
\hline immigrants & 48.497 \\
\hline want & 47.777 \\
\hline illegal & 46.424 \\
\hline pushback & 31.325 \\
\hline culture & 28.063 \\
\hline country & 23.718 \\
\hline Africans & 23.663 \\
\hline politicians & 18.874 \\
\hline desert & 18.273 \\
\hline UK & 18.130 \\
\hline integrate & 16.331 \\
\hline stop & 15.822 \\
\hline traditions & 15.663 \\
\hline pay & 13.848 \\
\hline sad & 13.052 \\
\hline
\end{tabular}

\subsection{Metaphorical extension}

While the content words' frequency and keyness measures seem to indeed be useful indicators of the main ideological values that underlie xenophobic and homophobic attitudes in Malta, they do not seem to precisely pinpoint them. Clearly, a more nuanced look at the meanings communicated in the text is necessary to fully uncover

${ }^{15}$ In this setting, the expression "pushback" refers to a policy that was sought to be enforced in Malta in 2013, but never materialised. According to this policy, all asylum seekers arriving in Malta would effectively be redirected back to Libya. 
the roots of xenophobia and homophobia in this setting; hence, the C.O.N.T.A.C.T. project's focus not only on quantitative but also at qualitative analysis. In this vein, the identification of the linguistic and rhetorical strategies used by the commentators, i.e. what we called tactics in the previous section, can offer significant insights not only in relation to the main concerns that can lead to the rise of discriminatory attitudes in the general public, but also in relation to the particular forms of expression that can be used to communicate such attitudes. ${ }^{16}$

Staying in the broader area of lexical meaning, we will now turn to show how the values identified by our interviewees as the main roots of xenophobia and homophobia in the Maltese society can also be discerned through the use of metaphors to refer to the relevant minorities in the subcorpora of the Maltese C.O.N.T.A.C.T. corpus we have been looking at so far. Our focus on metaphor is, again, not coincidental. Following from Lakoff and Johnson's conviction that "metaphor is pervasive in everyday life, not just in language but in thought and action [... and that] our ordinary conceptual system, in terms of which we both think and act, is fundamentally metaphorical in nature" (2003: 3), several critical discourse analysts of discrimination have shown that a number of negative metaphors appear to dominate discourse of minority groups (cf. Reisigl and Wodak 2001; Baker et al. 2008; KhosraviNik 2010; Musolff 2015; Kopytowska, Grabowski and Woźniak 2017; Baider and Kopytowska, this issue). In this setting, during their selection of words and phrases that will be used to express their opinion, several individuals opt to employ particular metaphorical vehicles that will successfully communicate their negative attitude towards a particular minority. As KhosraviNik, for example, discusses in relation to racist discourse, a number of studies have shown that "metaphors of aliens, water and natural disasters, pollution and impurity, war/fighting, house/building, disease/infection, animals, goods and the economy are salient to the argumentative structure of [relevant] discourses" (2010: 7).

In a similar trend, a quick look at the metaphors present in our two datasets with negative comments reveals a number of negative metaphors that occur consistently throughout the corpus and that corroborate the findings of the lexical analysis and the focus group interviews described above.

So, in the 365 comments that make up the corpus of negative comments targeted towards migrants, we identified 109 metaphors, which belong to the broad categories shown in Table 8. Again, the fact that the most common metaphor in this setting is that of migrants as invaders serves as further confirmation of the basic root of xenophobia that was identified in our focus group discussions being the perceived threat that migrants constitute for Malta's culture and its Euro-centric values.

\footnotetext{
${ }^{16}$ For an extensive discussion of this point, see Assimakopoulos et al. (2017).
} 
Special issue on The pragmatics of othering: Stereotyping, hate speech and legitimising violence

DOI:10.1515/lpp-2017-0010

Table 8: Metaphors in the Migration negative comments subcorpus.

\begin{tabular}{|l|l|}
\hline Metaphor & $\begin{array}{l}\text { Frequency in the migration negative comments } \\
\text { subcorpus }\end{array}$ \\
\hline Migrants as invaders & 41 \\
\hline Migrants as violent/terrorists & 31 \\
\hline Migrants as opportunists/scroungers & 31 \\
\hline Migrants as animals & 6 \\
\hline
\end{tabular}

Table 9: Metaphors in the LGBTIQ negative comments subcorpus.

\begin{tabular}{|l|l|}
\hline Metaphor & $\begin{array}{l}\text { Frequency in the LGBTIQ negative comments } \\
\text { subcorpus }\end{array}$ \\
\hline LGBTIQ persons as pushy & 32 \\
\hline LGBTIQ persons as abnormal beings & 24 \\
\hline LGBTIQ persons as perverts & 9 \\
\hline LGBTIQ persons as sick & 7 \\
\hline
\end{tabular}

Here are some representative examples of comments that explicitly communicate this perceived threat through metaphor:

The only way to stop this massive African invasion of Europe and save the Africans themselves is to send back ALL illegal immigrants including those already in Europe to send the message that no matter how many times they try and even if they reach Europe they shall ALL be sent back.

I call them PATRIOTIC, but then the word patriotic is a foregone conclusion for some people who prefer in seeing Malta sink under the mass exodus of these illegals then toe the national line!

Stop this insanity: help the Libyan police/coastguard to patrol Libya's shores to stop these illegal activities from becoming rescues at sea. These immigrants have no right to invade other countries. 
Stick up for your country not others that abandon theirs and do not have the guts to fix their own but illegally invade others!

A similar conclusion can also be drawn in relation to the LGBTIQ subcorpus of negative comments, which overall contained 72 metaphors in its 207 comments. As Table 9 indicates, the most common type of metaphor used in these comments may be that of force, through which commentators express their dismay at LGBTIQ organisations and individuals pushing their own agenda with disregard for the general population's received view, but all the remaining metaphors, which collectively outnumber those of force, can be directly linked to the religious concerns noted by our focus group interview participants. In this respect, apart from the metaphors of perversion, which are directly linked to religious ideas, metaphors of unnaturalness and arguably sickness too - can also be traced back to the Christian rhetorics, in which "gay sexual activity, if not orientation, is not uncommonly rendered a serious 'sin': an unnatural, abnormal deviant form of behaviour" (Hunt 2009: 2, emphasis our own). This much is also evident in the following representative examples from our corpus too:

The Church affirms that all human beings are created in God's image. Natural law makes it impossible to equate a homosexual relationship to a heterosexual relationship.

God has created humanity and has given it his loving laws for its own benefit. Regarding sexuality, he gave us the Sixth and Ninth Commandments. So, every sexual act outside of marriage is a grave sin that separates the sinner from God and puts them on the path to hell. Consequently, masturbation, homosexuality, adultery, fornication, sodomy, etc are condemned by God as evil acts.

That is what the Catholic teaching says and if we are Catholics we cannot just accommodate to something that God hates or that goes against His teaching!!!

The more they get informed about sexuality the more they want to do it. Why don $\mathrm{t}$ the education teach the LGBTQI THE NORMAL way as god wants?

\section{Concluding remarks}

Clearly, the issue of discriminatory discourse and the topic within it of the actual linguistic expression of the ideological values that underlie it are far too broad to tackle in a single paper, even if this paper reports on research undertaken in the context of a very small, albeit vibrant, country, like Malta is. That is why our aim in this paper has been rather modest. What we hope to have demonstrated through our argumentation and analysis is that even a quick look at the most obvious textual characteristics of a carefully sampled body of discriminatory discourse can provide significant insight into the roots of 
the phenomenon of discrimination in society. Taking xenophobic and homophobic attitudes in Malta as a test case, we showed how the particular mechanisms of identity construction that underlie the social practice of discrimination in this context can be identified through the textual analysis of discourse pertinent to the domains at hand. And since the aim is to approximate the values that trigger discrimination at a general level, the choice and sampling of the relevant discourse on which textual analysis is to be performed is pivotal. In this respect, we believe that publicly available online comments to news portal stories are particularly useful in revealing the general public's sentiment, as they constitute instances of spontaneous, and often unfiltered, talk. All in all, since our admittedly crude - textual analysis appears to largely corroborate the conclusions independently reached during our focus group interviews, we feel that this case study has successfully shown that the tools available to linguists and discourse analysts alike can play a crucial role in understanding and eventually countering discrimination. And given the increasing focus of policy, at least in the EU, on combatting hate speech, this is not a trivial conclusion.

Obviously, there is a lot more to the textual analysis of discriminatory discourse than our discussion here has managed to reveal. Once all the strategies used to express not only a negative, but also a positive disposition towards the minorities under question are thoroughly examined, a far more nuanced picture of xenophobic and homophobic attitudes in the Maltese context will undoubtedly emerge. However, this would be a topic for another paper, which we intend to pursue on another occasion in the not too distant future.

\section{Acknowledgements}

The research reported in this paper has been carried out as part of the C.O.N.T.A.C.T. project, which has received co-funding from the Rights, Equality \& Citizenship Programme of the European Commission Directorate-General for Justice and Consumers (JUST/2014/RRAC/AG/HATE/6706). We are particularly grateful to Fabienne Baider and Sharon Millar for coming up with the original methodology on which this research is based. Finally, we would also like to thank the editors of this special issue for their patience and sound editorial advice.

\section{References}

Anthony, Lawrence. 2014. AntConc Software (Version 3.4.4m). Tokyo, Japan: Waseda University. (http://www.laurenceanthony.net/). Accessed on 19th October 2017.

Assimakopoulos, Stavros \& Rebecca Vella Muskat. 2017. Xenophobic and homophobic attitudes: National report for Malta. Msida: University of Malta. http://staff.um.edu.mt/_data/assets/pdf_ file/0007/328903/CONTACTNationalreportforMaltaUM-Malta.pdf(accessed 19 October 2017). 
Assimakopoulos, Stavros, Fabienne H. Baider \& Sharon Millar (eds.). 2017. Online hate speech in the European Union: a discourse-analytic perspective. Berlin: Springer.

Baider, Fabienne H. \& Maria Constantinou. 2017. "Burn the antifa traitors at the stake...": Transnational political cyber-exchanges, proximisation of emotions. In Istvan Kecskes \& Stavros Assimakopoulos (eds.), Current issues in intercultural pragmatics, 75-104. Amsterdam/Philadelphia: John Benjamins.

Baider, Fabienne. 2013. The saliency hypothesis: affects and emotions. In Istvan Kecskes \& Jesús Romero-Trillo (eds.), Research trends in intercultural pragmatics, 7-25. Berlin: Mouton de Gruyter.

Baker, Paul, Costas Gabrielatos, Majid KhosraviNik, Michał Krzyżanowski, Tony McEnery \& Ruth Wodak. 2008. A useful methodological synergy? Combining critical discourse analysis and corpus linguistics to examine discourses of refugees and asylum seekers in the UK press. Discourse and Society 19. 273-306.

Baron, Alistair, Paul Rayson \& Dawn Archer. 2009. Word frequency and key word statistics in historical corpus linguistics. Anglistik: International Journal of English Studies 20. 41-67.

Cammaerts, Bart. 2009. Radical pluralism and free speech in online public spaces. International Journal of Cultural Studies 12. 555-575.

de Beaugrande, Robert. 2004. Critical discourse analysis from the perspective of ecologism: the discourse of the "new patriotism" for the "new secrecy". Critical Discourse Studies 1. 113-145.

Domingo, David, Thorsten Quandt, Ari Heinonen, Steve Paulussen, Jane B. Singer \& Marina Vujnovic. 2008. Participatory journalism practices in the media and beyond. Journalism Practice 2.326-342.

Erjavec, Karmen \& Melita Poler Kovačič. 2012. "You don’t understand, this is a new war!" Analysis of hate speech in news web sites' comments. Mass Communication and Society 15. 899-920.

Fairclough, Norman. 1992. Discourse and social change. Cambridge: Polity Press.

Fairclough, Norman. 1995. Critical Discourse Analysis: the critical study of language. London/New York: Longman.

Firth, John Rupert. 1935. The technique of semantics. Transactions of the Philological Society 34. 36-73.

Hunt, Stephen. 2009. Saints and sinners: Contemporary Christianity and LGBT sexualities. In Stephen Hunt (ed.), Contemporary Christianity and LGBT sexualities, 1-22. London/New York: Routledge.

Josey, Christopher S. 2010. Hate speech and identity: An analysis of neo racism and the indexing of identity. Discourse \& Society 21. 27-39.

KhosraviNik, Majid. 2010. The representation of refugees, asylum seekers and immigrants in British newspapers: a critical discourse analysis. Journal of Language and Politics 9. 1-28.

Kopytowska, Monika, Łukasz Grabowski \& Julita Woźniak. 2017. Mobilizing against the Other: cyberhate, refugee crisis and proximization. In Monika Kopytowska (ed.), Contemporary discourses of hate and radicalism across space and genres, 57-97. Amsterdam/Philadelphia: John Benjamins.

Kopytowska, Monika, Julita Woźniak \& Łukasz Grabowski. 2017. From "patriotism" to hate: axiological urgency in online comments related to refugees. In Stavros Assimakopoulos, Fabienne H. Baider \& Sharon Millar (eds.), Online hate speech in the European Union: a discourse-analytic perspective, 42-51. Berlin: Springer. 
Special issue on The pragmatics of othering: Stereotyping, hate speech and legitimising violence

DOI:10.1515/lpp-2017-0010

Lakoff, George \& Mark Johnson. 1980. Metaphors we live by. Chicago: The University of Chicago Press.

Love, Robbie \& Paul Baker. 2015. The hate that dare not speak its name? Journal of Language Aggression and Conflict 3. 57-86.

Millar, Sharon, Fabienne H. Baider \& Stavros Assimakopoulos. 2017. The C.O.N.T.A.C.T. methodological approach. In Stavros Assimakopoulos, Fabienne H. Baider \& Sharon Millar (eds.), Online hate speech in the European Union: a discourse-analytic perspective. Berlin: Springer.

Musolff, Andreas. 2015. Dehumanizing metaphors in UK immigrant debates in press and online media. Journal of Language Aggression and Conflict 3. 41-56.

Pollach, Irene. 2012. Taming textual data: The contribution of corpus linguistics to computer-aided text analysis. Organizational Research Methods 15.263-287.

Reisigl, Martin \& Ruth Wodak. 2001. Discourse and discrimination: rhetorics of racism and antisemitism. London/New York: Routledge.

Rowe, Charlie. 2009. E-mail play and accelerated change. In Charlie Rowe \& Eva Lia Wyss (eds.), Language and new media: linguistic, cultural, and technological evolutions, 75-98. Cresskill, NJ: Hampton Press.

Scott, Mike. 1997. PC analysis of key words - And key key words. System 25. 233-245.

Teo, Peter. 2000. Racism in the news: A critical discourse analysis of news reporting in two Australian newspapers. Discourse \& Society 11. 7-49.

Triandafyllidou, Anna. 2000. The political discourse on immigration in southern Europe: a critical analysis. Journal of Community and Applied Social Psychology 10. 373-389.

van Dijk, Teun A.1993. Elite discourse and the reproduction of racism. In Rita Kirk Whillock \& David Slayden (eds.), Hate speech, 1-27. London: Sage Publications.

Wodak, Ruth \& Michael Meyer. 2009. Critical discourse analysis: history, agenda, theory and methodology. In Ruth Wodak \& Michael Meyer (eds.), Methods of Critical Discourse Analysis ( $2^{\text {nd }}$ edn.), 1-33. London: Sage Publications. 


\begin{abstract}
About the Authors
Stavros Assimakopoulos is Senior Lecturer in Linguistics at the University of Malta. His research lies in the interface of linguistics, philosophy and cognitive psychology and focuses on inferential pragmatics and (critical) discourse analysis. He recently edited three volumes: Pragmatics at its interfaces (Mouton de Gruyter, 2017), Current issues in intercultural pragmatics (John Benjamins, 2017; with Istvan Kecskes) and Online hate speech in the European Union: A discourse-analytic perspective (Springer, 2017; with Fabienne H. Baider and Sharon Millar).
\end{abstract}

Rebecca Vella Muskat is a doctoral candidate in Linguistics at the University of Malta. Her main interests are in the interface of language and society. As such she uses linguistic methods, in particular critical discourse analysis, to examine ideological stances evident through linguistic structures. She currently works as a researcher on the C.O.N.T.A.C.T. project at the University of Malta and she is a project officer with a local NGO working in the area of human rights and equality.

\title{
Address
}

Stavros Assimakopoulos

Institute of Linguistics and Language Technology, Room 119

University of Malta

Msida, MSD 2080, Malta

e-mail: stavros.assimakopoulos@um.edu.mt 